\title{
Limits to Plasticity in Gray Wolf, Canis lupus, Pack Structure: Conservation Implications for Recovering Populations
}

\author{
Thomas M. Gehring ${ }^{1}$, Bruce E. Kohn ${ }^{2}$, Joelle L. Gehring ${ }^{1}$, and Eric M. Anderson ${ }^{3}$ \\ ${ }^{1}$ Department of Biology, Central Michigan University, Mt. Pleasant, Wisconsin 48859 USA \\ ${ }^{2}$ Wisconsin Department of Natural Resources, Ranger Station, Box 576, Rhinelander, Wisconsin 54501 USA \\ ${ }^{3}$ College of Natural Resources, University of Wisconsin-Stevens Point, Stevens Point, Wisconsin 54481 USA
}

Gehring, Thomas M., Bruce E. Kohn, Joelle L. Gehring, and Eric M. Anderson. 2003. Limits to plasticity in Gray Wolf, Canis lupus, pack structure: conservation implications for recovering populations. Canadian Field-Naturalist 117(2): 419-423.

We documented the dynamics of the Five Corners Pack (FCP) in east-central Minnesota and northwestern Wisconsin through the loss and replacement of four alpha-females over a four-year period. This pack remained intact and produced offspring during the period despite the annual loss of the alpha female. However, we observed a disintegration of the pack after four consecutive alpha females died, at least two of which were due to illegal killing by humans. Our observations generally support the hypothesis that "single-parent" wolf packs may be more prevalent in areas with low densities of wolves and high densities of ungulate prey. Our observations also highlight the need to assess the potential negative impacts of wolf removal on pack structure and persistence at local and regional scales.

Key Words: Gray Wolf, Canis lupus, disease, edge effects, behavior, mortality, radio telemetry, recovering populations, social structure, Minnesota, Wisconsin.

During 1992-1996, we monitored Gray Wolves (Canis lupus) by means of radio telemetry as part of a larger study on the effects of highway development on wolf movements and population dynamics (Gehring 1995; Kohn et al. 1995*, 1999*, 2000*). Herein, we report on the plastic nature of pack structure and reproductive ecology of the Five Corners Pack (FCP) in east-central Minnesota and northwestern Wisconsin. We also highlight the limits to this plasticity relative to the disintegration of pack dynamics coincident with dispersal and high rates of mortality for reproducing females. Although limited to intensive observations of one pack, our results have implications for the management of wolf populations in the upper Midwest.

\section{Methods}

Wolves were captured in east-central Minnesota and northwestern Wisconsin during May-August in modified \#14 Newhouse steel traps (Kuehn et al. 1986). Captured wolves were immobilized by an intra-muscular injection of ketamine hydrochloride and xylazine hydrochloride. Once immobilized, wolves were fitted with a radio collar and ear-tagged with a uniquely numbered plastic tag (Kohn et al. 2000*). Radio-collared wolves were monitored by radio telemetry at least 1-2 times weekly from fixed-wing aircraft (Mech 1974), and an attempt was made to relocate individuals daily using a vehicle-mounted antenna system (Gehring 1995; Shelley and Anderson 1995*). We maintained a minimum of one radio-collared wolf in each study pack.

Radio telemetry was used to determine movements, home range, and population dynamics of wolves in our study area. Additionally, we conducted howling surveys during July-September each year to assess pup produc- tion (Harrington and Mech 1982; Fuller and Sampson 1988). We also used howling surveys and track counts in the fall and winter to determine recruitment of pups into wolf packs and pack size (Rothman and Mech 1979; Harrington and Mech 1982; Kohn et al. 2000*).

\section{Results}

\section{Temporal Dynamics}

The FCP consisted of one to seven wolves during the study period; however, pack composition (most notably alpha-females) differed between years (Gehring 1995). During fall 1991, W149 (alpha-female 1) dispersed from the Moose Lake Pack in northwestern Wisconsin (approximately $70 \mathrm{~km}$ northeast of the FCP) to the FCP and assumed alpha status, joining four other wolves. Thus, alpha-female 1 likely replaced the previous FCP alpha-female. During May 1992, the Wisconsin Department of Natural Resources captured and radio-collared a yearling female wolf (W177, Wydeven 1994*). Based on howling surveys, we determined that alpha-female 1 produced an estimated six pups before her death in June 1992. Alpha-female 1's carcass was found discarded along a roadside near the northern extent of the FCP territory (Shelley and Anderson 1995*; Gehring 1995). Necropsy results indicated that she had been killed in a snare (Kohn et al. 1995*, $2000 *)$. After the death of alpha-female 1, W177 (yearling female) dispersed from the FCP and eventually formed the Price Creek Pack in north-central Wisconsin (Wydeven 1994*). Based on howling surveys and track counts, we determined that a minimum of two pups survived into the winter (Gehring 1995).

In August 1992, W145 (alpha-female 2) dispersed to the FCP from the Crotte Creek Pack in northwestern 
Wisconsin (approximately $50 \mathrm{~km}$ northeast of the FCP). Based on the arrival date of alpha-female 2 into the FCP, we determined that she likely aided in the rearing of alpha-female 1's pups. Our howling surveys indicated that alpha-female 2 successfully produced an estimated four pups in 1993 before her death in late July 1993 by apparently illegal means. Our howling surveys later confirmed that all pups survived into the fall. Although her carcass was never recovered, alpha-female 2's cut-off collar was found in a stream near Minnesota State Highway 48 (approximately $3.5 \mathrm{~km}$ east of the site where the carcass of alpha-female 1 was found). In 1993, the FCP contained an estimated three adult/yearling wolves (including W188, a radio-collared yearling male) after the death of alpha-female 2. However, based on howling surveys and track counts, we estimated that the pack had grown to seven members by winter 1994 (Gehring 1995).

Concurrent with events in the FCP, during winter 1992-93 and 1993-94, two wolf packs bordering the FCP maintained three wolves (Crex Meadows Pack, south of FCP) and up to five wolves (Sand Creek Pack, northwest of FCP, Figure 1). During summer 1993, the United States Department of Agriculture Animal and Plant Health Inspection Service, Wildlife Services (APHIS-WS), killed five wolves in the Sand Creek Pack (SCP) following livestock depredations, and this was believed to be the end of this pack (Wydeven and Megown 1996a*). During spring 1994, W188 (male from FCP) dispersed to the former SCP territory and re-established the pack with one other wolf.

During May 1994, we captured an lactating adult female wolf (W221) in the FCP. This wolf, which became W221 (alpha-female 3), originally had been captured and ear-tagged as a pup in the Rainbow Lake Pack, northwestern Wisconsin (approximately $120 \mathrm{~km}$ northeast of the FCP). Based on her arrival date into the FCP, alpha-female 3 likely aided in the rearing of alpha-female 2's pups. Alpha-female 3 produced a minimum of one pup during 1994 (Gehring 1995). During winter 1994-1995, the FCP was believed to contain only two wolves, whereas the Crex Meadows Pack (CMP) had grown to eight wolves and the CMP began using the southern portion of the FCP territory (Wydeven and Megown 1996a*). During winter 19951996, the FCP contained W221 and a possible second wolf (Wydeven and Megown 1996b*). In May 1996, alpha-female 3 was killed by intra- or inter-pack strife north of the previous boundary of the FCP territory (Kohn et al. 2000*, Figure 1). During June-July 1996, APHIS-WS also killed four wolves in the SCP as part of depredation-control activities. Following the death of alpha-female 3 , the FCP structure appears to have disintegrated and the adjacent CMP remained in the southern half of the former FCP territory (Kohn et al. 1995*, 1999*; Wydeven and Megown 1996a). During 1996-1998, no additional signs of the FCP were reported, whereas the CMP maintained an esti- mated three wolves (Wydeven and Cervantes 1997*; Wydeven et al. 1998*).

\section{Discussion}

Boyd and Jimenez (1994) reported three cases of lone wolves and two instances where a pack of female wolves successfully reared young after the death of a mate. Boyd and Jimenez (1994) suggested that the successful rearing of pups by packs that contain only one surviving mate may have been related to the low density of wolves and high density of ungulate prey in their study area. Data from the FCP may lend some support to this hypothesis. Wolf densities in our study area were low (2-3 wolves/1000 km²; Gehring 1995), and deer densities in the FCP were high (8.5-8.9 deer $/ \mathrm{km}^{2}$; Gehring 1995). However, we suggest that the FCP was unique because it successfully reared pups ranging in ages from 8-13 weeks old over three consecutive years despite the annual loss of the alphafemale. The short-term maintenance of the FCP was aided by the high fecundity of these females and the rapid replacement of alpha-females each year. However, the instability in the FCP structure, due to natural mortality and consistently high human-caused mortality, probably led to the ultimate demise of this pack, highlighting the ephemeral nature of wolf packs in a recovering wolf population, particularly in semi-agricultural landscapes.

\section{Managing Wolf Populations}

Our observations also highlight the need to incorporate the complexity of wolf pack dynamics into long-term wolf management plans and policies in the Great Lakes Region as well as other regions. In particular, wolf removal as part of livestock-depredation programs can alter wolf pack composition (Gehring 1995). Policy makers developing wolf depredation management strategies should therefore assess the potential negative impacts of wolf removal on pack structure and persistence, especially in recovering populations (Haber 1996). The proposed zone system for wolf management, whereby different areas have different management prescriptions, in the Great Lakes Region (Mech 1995; Wisconsin Department of Natural Resources 1999*; Minnesota Department of Natural Resources 2001*) may lead to locally unstable pack dynamics if sink habitats are formed by depredation control or harvest activities. Under a zone system, an established wolf pack near the edge of a protected zone may still be vulnerable to external human-related mortality (Woodroffe and Ginsberg 1998; Laurance 2000). Furthermore, all wolves dispersing from established wolf packs in the protected zone could be vulnerable. Woodroffe and Ginsberg (1998) demonstrated vulnerability to populations of large mammalian carnivores due to edge effects in the form of humancaused mortality outside of reserves (i.e., edge effects expressed over large spatial scales, sensu Laurance 2000). Carnivores with large home ranges were most 


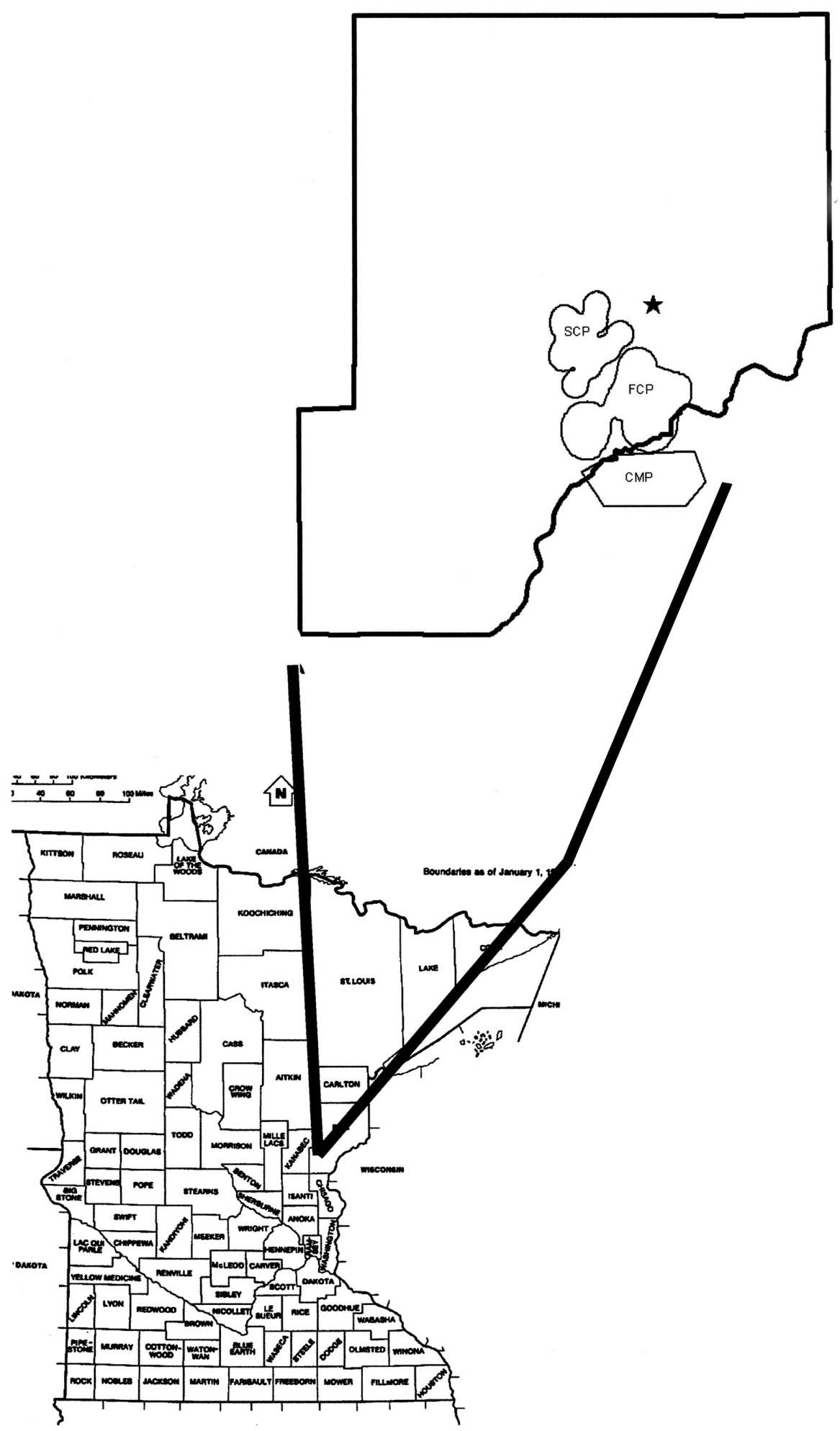

FIGURE 1. Location of wolf packs monitored during 1992-96 in Pine County, Minnesota and Burnett County, Wisconsin. Abbreviations include: CMP $=$ Crex Meadows Pack; FCP $=$ Five Corners Pack; SCP $=$ Sand Creek Pack. The star indicates the location where W221 was found dead in 1996. 
vulnerable independent of local population densities, suggesting that the formation of population sinks at reserve margins leads to depleted carnivore numbers and might ultimately lead to the extinction of the reserve population (Woodroffe and Ginsberg 1998).

We draw a parallel to the present discussion in the Great Lakes Region relative to various proposals to establish a management zone system across both Minnesota and Wisconsin for wolf management (Wisconsin Department of Natural Resources 1999*; Minnesota Department of Natural Resources 2001*). Zones would differ relative to the extent to which lethal control and translocation are allowed. For example, northern regions of Wisconsin would serve as a quasireserve (i.e., some lethal control and translocation is allowed) for wolves, whereas southern Wisconsin would be a wolf-free zone with potentially high rates of mortality (e.g., mortality due to vehicular collisions and active killing by humans) for wolves occupying this zone (Wisconsin Department of Natural Resources $1999 *)$. We suggest that such a management scenario could result in edge effects on zones where wolves are afforded more protection by the formation of sink habitats in adjacent management zones, thereby jeopardizing the viability of wolves in more protected zones.

Our observations on the FCP suggest that this pack's region may have served as a sink habitat for a large portion of Wisconsin's recovering wolf population. Thus, the presence of sink habitats, particularly on the periphery of recovering populations, could potentially slow the recovery process. We base this suggestion on the temporarily high replacement rate of alpha females in the FCP, all of which dispersed out of the recovering Wisconsin population. We suggest that wolf management plans in the Great Lakes Region must incorporate scientifically-based strategies for ameliorating the potential negative impacts of large-scale edge effects on wolf pack structure and long-term population viability.

\section{Conservation Implications}

One strategy, in addition to public education, that might (1) reduce the mortality of wolves associated with depredation control activities; (2) reduce wolfhuman conflicts (e.g., illegal killing); and (3) minimize the instability of pack dynamics, would be an in situ management approach of depredation. That is, rather than using a reactionary approach by removing wolves on a case-by-case basis, managers might use proactive management by taking an integrated approach (sensu Fritts et al. 1992*) and attempt to reduce or prevent depredations caused by resident wolves (Gehring et al. 1996). Such an approach could include the use of non-lethal tools as part of an arsenal of preventative measures for reducing depredations. These measures might include: improved livestock husbandry (Gehring et al. 1999), the use of shock-collars (Hawley et al. 2003), and the use of guard animals.

\section{Acknowledgments}

Funding and logistical support were provided by the Wisconsin Department of Natural Resources (Federal Aid in Wildlife Restoration Act, Pittman-Robertson Project W-141-R); Wisconsin Department of Transportation; and University of Wisconsin-Stevens Point. We also thank the Minnesota Department of Natural Resources, USDA APHIS-Wildlife Services, and U. S. Fish \& Wildlife Service for additional logistical support of this study. We thank J. B. Dunning, Jr. for his constructive comments that improved the manuscript.

Documents Cited (marked $*$ in the text)

Fritts, S. H., W. J. Paul, L. D. Mech, and D. P. Scott. 1992. Trends and management of wolf-livestock conflicts in Minnesota. United States Fish and Wildlife Service Resource Publication Number 181.

Kohn, B. E., D. P. Shelley, T. M. Gehring, D. M. Unger, and E. M. Anderson. 1995. Impacts of Highway 53 development on timber wolves. Wisconsin Department of Natural Resources. Report \#3. 17 pages.

Kohn, B., J. Frair, D. Unger, T. Gehring, D. Shelley, E. Anderson, and P. Keenlance. 1999. Impacts of a highway expansion project on wolves in northwestern Wisconsin: preliminary findings. Proceedings of The International Conference on Wildlife Ecology and Transportation III, Missoula, Montana.

Kohn, B., J. Frair, D. Unger, T. Gehring, D. Shelley, E. Anderson, and P. Keenlance. 2000. Impacts of the U.S. Highway 53 expansion project on wolves in northwestern Wisconsin: final report. Wisconsin Department of Natural Resources. 49 pages.

Minnesota Department of Natural Resources. 2001. Minnesota wolf management plan. St. Paul, Minnesota. 80 pages.

Shelley, D. P., and E. M. Anderson. 1995. Effects of vehicular traffic on and ecology of timber wolves in northwestern Wisconsin and east-central Minnesota. Final Report. University of Wisconsin-Stevens Point, Stevens Point. 100 pages.

Wisconsin Department of Natural Resources. 1999. Wisconsin wolf management plan. Madison, Wisconsin. PUBL-ER-099 99. 74 pages.

Wydeven, A. P. 1994. Status of the timber wolf in Wisconsin. Wisconsin Endangered Resources Report \#102. Wisconsin Department of Natural Resources. 20 pages.

Wydeven, A. P., and N. M. Cervantes. 1997. Progress report of wolf population monitoring in Wisconsin for the period April - September 1997. Wisconsin Department of Natural Resources. 20 pages.

Wydeven, A. P., and R. A. Megown. 1996a. Progress report of wolf population monitoring in Wisconsin for the period October - December 1995. Wisconsin Department of Natural Resources. 11 pages.

Wydeven, A. P., and R. A. Megown. 1996b. Progress report of wolf population monitoring in Wisconsin for the period April - June 1996. Wisconsin Department of Natural Resources. 18 pages.

Wydeven, A. P., B. E. Kohn, R. P. Thiel, R. N. Schultz, and S. R. Boles. 1998. Progress report of wolf population monitoring in Wisconsin for the period April - September 1998. Wisconsin Department of Natural Resources. 16 pages. 


\section{Literature Cited}

Boyd, D. K., and M. D. Jimenez. 1994. Successful rearing of young by wild wolves without mates. Journal of Mammalogy 75: 14-17.

Fuller, T. K., and B. A. Sampson. 1988. Evaluation of a simulated howling survey for wolves. Journal of Wildlife Management 52: 60-63.

Gehring, T. M. 1995. Winter wolf movements in northwestern Wisconsin and east-central Minnesota: a quantitative approach. M.S. thesis, University of WisconsinStevens Point, Stevens Point. 132 pages.

Gehring, T. M., J. L. Gehring, and B. E. Kohn. 1999. Management of wolf-caused livestock depredations: the farmer's role. $129^{\text {th }}$ Annual Conference of the Wisconsin Academy of Sciences, Arts and Letters. Stevens Point, Wisconsin.

Gehring, T. M., J. L. Gehring, M. A. Beckel, and M. A. Callahan. 1996. Recovering wolf populations. Conservation Biology 10: 5-6.

Haber, G. C. 1996. Biological, conservation, and ethical implications of exploiting and controlling wolves. Conservation Biology 10: 1068-1081.

Harrington, F. H., and L. D. Mech. 1982. An analysis of howling response parameters useful for wolf pack censusing. Journal of Wildlife Management 46: 686-693.
Hawley, J. E., T. M. Gehring, S. Rossler, R. N. Schultz, and A. P. Wydeven. 2003. Experimental assessment of a non-lethal control method for reducing conflict. World Wolf Congress, Banff, Alberta, Canada.

Kuehn, D. W., T. K. Fuller, L. D. Mech, W. J. Paul, S. H. Fritts, and W. E. Berg. 1986. Trap-related injuries to gray wolves in Minnesota. Journal of Wildlife Management 50: 90-91.

Laurance, W. F. 2000. Do edge effects occur over large spatial scales? Trends in Ecology and Evolution 15: 134-135.

Mech, L. D. 1974. Current techniques in the study of elusive wilderness carnivores. Pages 315-324 in Proceedings of the eleventh international congress on game biology, Stockholm, Sweden.

Mech, L. D. 1995. The challenge and opportunity of recovering wolf populations. Conservation Biology 9: 270-278.

Rothman, R. J., and L. D. Mech. 1979. Scent marking in lone wolves and newly formed pairs. Animal Behavior 17: 750-760.

Woodroffe, R., and J. R. Ginsberg. 1998. Edge effects and the extinction of populations inside protected areas. Science 280: $2126-2128$.

Received 5 November 2001

Accepted 19 January 2004 